\title{
Robustness against the effects of multipath in an ISDB-T LDM broadcast system using diversity at reception
}

\author{
Ricardo Seriacopi Rabaça \\ Cristiano Akamine \\ George Henrique Maranhão Garcia de Oliveira \\ Thiago Montanaro Sapia
}




\title{
Robustness against the effects of multipath in an ISDB-T LDM broadcast system using diversity at reception
}

\author{
Ricardo Seriacopi Rabaça, Cristiano Akamine, George Henrique Maranhão Garcia de Oliveira and \\ Thiago Montanaro Sapia \\ Electrical Engineering and Computing Program \\ Mackenzie Presbyterian University \\ Sao Paulo, Brazil \\ ricardo_sr2@hotmail.com, akamine@ieee.org, george.oliveira@mackenzie.br, tmsapia@gmail.com
}

\begin{abstract}
This paper presents the ISDB-T LDM system, with the Core Layer fully compatible with the traditional ISDB-T and the Enhanced Layer using the Non-Uniform Constellation 64QNUC, in order to improve spectral efficiency, performance, robustness and useful bit rate, so that it is possible to use it for UHDTV applications. In order to reach these goals, in addition to the LDM technique, the LDPC encoder/decoder concatenated with the $\mathrm{BCH}$ were used. The SDR/GRC implementation was used and the reception diversity was achieved by the use of the MRC method. To prove its efficiency, some tests were performed using the proposed system in environments with AWGN and multipath channels.
\end{abstract}

Index Terms - Integrated Services Digital Broadcasting Terrestrial (ISDB-T), Layer Division Multiplexing (LDM), Maximal Ratio Combining (MRC), Low-Density Parity Check (LDPC), Software Defined Radio (SDR), GNU Radio Companion (GRC), multipath channels.

\section{INTRODUCTION}

The demand for better transmission and reception conditions, as well as higher transmission rates on wireless networks, has led to the need for more in-depth studies about the benefits that can be obtained with the use of more than one transmission/reception antenna in communication systems, in case they are under the fading effect [1].

The transmissions of terrestrial broadcasting are reflected by buildings and mountains; i.e., the propagation tends to be multipath environment. To resist multipath interference, the ISDB-T uses the orthogonal frequency division multiplexing (OFDM) modulation scheme. However, its robustness is not as good in severe multipath environments with long-delay waves exceeding the guard interval (GI) or high power multipath waves [2]. Therefore, additional techniques are required, such as the use of the MRC method (diversity at reception) and the use of LDM.

The evolution of Digital Terrestrial Television Broadcasting

This work was supported in part by the Coordination for the Improvement of Higher Education Personnel (CAPES), National Research and Educational Network (RNP), National Counsel of Technological and Scientific Development (CNPq) and MackPesquisa.
(DTTB) also requires greater robustness against interference. The new terrestrial broadcasters challenge is to transmit in Ultra High Definition Television (UHDTV). Therefore, it is necessary to use efficiently the spectrum since part of the DTV spectrum is used by wireless broadband services [3].

Some DTV systems are not able to support the requested bit rate and are not robust enough to transmit/receive UHDTV services. However, the substitution of a broadcasting system is not economically viable because it requires the exchange of receivers by all the population [4]. With the communication system created by [4], it is possible to maintain the compatibility of the receivers already installed and increase spectral efficiency by using new modulation, coding and diversity techniques, even in several types of transmission channels with multipath.

The modern Advanced Television Systems Committee (ATSC) 3.0 recommends the use of multiple antennas for transmission and reception besides allowing UHDTV transmission with the use of the LDM modulation technique [5].

The diversity can be defined as a set of versions of the signal transmitted which suffers different attenuations by the channel. This technique consists in the handling of these independent versions of the same signal in order to minimize the effects of the selective fading and also of the transmission channel [6]. An example of interference that occurs in the transmission channel and which commonly appears in digital TV systems is caused by reflection of the signals before they are received by the receiving antennas (multipath). There are some methods of diversity that can be used, such as, time diversity, space diversity and frequency diversity [7].

The purpose of this paper is to test the effect of multipath in the modified version of ISDB-T created by [8]. The system uses LDM technique and Non-Uniform Constellation (NUC). The Core Layer (CL) is compatible with the traditional ISDB-T [9] and the Enhanced Layer (EL) uses Bose, Chaudhuri, and Hocquenghem (BCH) and LPDC codes. Moreover, the MRC method at reception is used in order to improve robustness, bit rate and spectral efficiency [4].

These parameters are requirements for new services such as 
UHDTV without the need to replace the current system in the process of implementing the new technology [4].

The system proposed was implemented in SDR by using GNU Radio Companion (GRC) software. The GRC is a free and open-source software development toolkit that provides signal processing blocks to implement software radios. It can be used with readily-available low-cost external RF hardware to create software-defined radios, or without hardware in a simulation-like environment [10].

This paper is organized into seven sections. In Section II, the main characteristics and advantages of the LDM are presented. Section III contains the most relevant information about the ISDB-T. Section IV presents the characteristics of the maximal ratio combining and the benefits it brings to the system. Section $\mathrm{V}$ shows the main characteristics about the transmission channel. Section VI shows the implementation and results of the modified version of ISDB-T with diversity at the reception. And finally, Section VII presents the conclusion of this paper.

\section{LAYER DIVISION MULTIPLEXING}

The LDM technology allows the transmission of data divided by layers using different power levels, at the same time and frequency. The LDM's main advantages are its efficient use of the spectrum, the increase in the amount of data transmitted [11], robustness against co-channel interference and multipath distortion. Furthermore, the lowest level layer is compatible with any high rate digital broadcasting technology [12].

The EL suffers an attenuation of (Injection Level) dB compared to the CL. This attenuation is performed by multiplying the EL per alpha factor, which has been defined in the ATSC 3.0 standard [13]. Each layer is encoded and mapped separately and then added together. After this step, the combined signal has a power equivalent to the sum of the CL and EL signal powers. Therefore, a power normalization of the combined signal is required, which is performed by its multiplication per beta factor. After this process, the resulting signal is modulated in (OFDM) and the guard interval is inserted [4]. The LDM demodulation is the inverse process: the guard interval is removed, the OFDM demodulation is applied, channel estimation, equalization and the MRC method are realized. A power denormalization is required, so a (beta factor) ${ }^{-1}$ multiplication is applied and then the CL is demapped and decoded [8]. To decode the EL, it is necessary to encode the CL again and then subtract it from the received signal (this process requires a buffer). The EL level is recovered by the (alpha factor) $^{-1}$ multiplication and then this layer can be demapped and decoded [14]. However, for a good performance of the LDM technique, an efficient error correction code is required. Therefore, the concatenated $\mathrm{BCH}$ and LDPC codes were used in order to reduce the error floor (phenomenon encountered in modern iterated sparse graph-based error correction codes) [8], [15].

\section{INTEGRATED SERVICES Digital BROADCASTING TERRESTRIAL}

The ISDB-T is a broadcast system based on Band Segmented Transmission-OFDM (BST-OFDM) which makes use of 13 segments to transmit data and 1 segment as guard band [8]. These segments create up to 3 different layers: A, B and C. Layer A is used to 1seg (mobile), layer B to Standard Definition Television (SDTV) and layer C to High Definition Television (HDTV), but most TV channel transmitters use layer A for 1seg and layer B to HDTV [15], [4]. The bandwidth required for the system can be of 6,7 or $8 \mathrm{MHz}$. The ISDB-T uses shortened Reed Solomon (RS) $(188,204,8)$ and convolutional coder with rate of $1 / 2(\mathrm{G} 1=171 \mathrm{oct} ; \mathrm{G} 2=133 \mathrm{oct})$ and puncture of $1 / 2$, $2 / 3,3 / 4,5 / 6$ or $7 / 8$ [16], [17].

After the RS encoder, the CL uses an energy dispersal to prevent errors due to long sequence of bits with the same value. Then, it is realized a byte interleaving in order to increase the efficiency of RS encoder [16], [17].

The ISDB-T standard uses modulation methods as DQPSK, QPSK, 16-QAM and 64-QAM. A time interleaver is used to increase robustness against impulsive noise and a frequency interleaver is applied to prevent errors from selective fading [4]. The time interleaving length, considering mode $3(8 \mathrm{k})$ and guard interval 1/16, can be adjusted for $0,102,204$ or $407 \mathrm{~ms}$. After this step, which scrambles the segments to ensure the appropriate segment structure, some delays are used in order to maintain synchronism [4]. Finally, the frame structure is built using 204 symbols OFDM [8].

After OFDM modulation, a part of the original signal (Guard Interval), is inserted to prevent errors due to multipath. The rates can be $1 / 4,1 / 8,1 / 16$ or $1 / 32$ [16], [17].

\section{MaXimal Ratio Combining}

In order to achieve improvements in transmission and reception with the use of the ISDB-T, the MRC method can be used where the receiver assigns a gain, proportional to the signal-to-noise ratio (SNR), to each of the signals of each available antenna and then combines them [7].

The attributed gain to each signal is given by Equation 1, where $r$ is the signal envelope in question and $\sigma^{2}$ is the noise variance [18].

$$
g=\frac{r}{\sigma^{2}}
$$

The SNR after the combination is given by Equation 2 [18].

$$
S N R=\frac{\sqrt{r_{1}+\cdots+r_{n}}}{\sqrt{\sigma^{2}}}
$$

To calculate the gain of each antenna, Equation 3 is used, where $S N R_{x}$ is the signal-to-noise ratio of the antenna in question [18].

$$
g_{x}=10^{S N R_{x} / 10}
$$

After this process, the linear combination is performed by means of Equation 4, where $R$ is a line matrix composed by the 
symbol received by each antenna, $G$ is a line matrix composed by the gains of each antenna and $N_{\text {ant }}$ is the total number of antennas in the system [18].

$$
M R C=\frac{R G^{\prime}}{\sum_{x=1}^{N a n t} g_{x}}
$$

The information about all the channels is used with this technique to obtain a more reliable received signal [7]. The drawback of this method is that it requires accurate estimates of the instantaneous signal level and average noise power for a better performance. In addition, it requires the use of more than one channel estimator working in parallel [4].

The SNR estimation for each branch is performed digitally using the pilot carriers [4]. In order to do so, the difference between the pilot carriers positions received and their ideal positions in the scatter diagram are calculated according to Equation 5, where $I$ is the number of pilot carriers known as Auxiliary Channel (AC) and Transmission and Multiplexing Configuration Control (TMCC) and $Y$ is the vector containing the value of the pilot carriers AC and TMCC [19].

$S N R=10 \cdot \log _{10} \frac{1}{I} \cdot \sum_{i=1}^{I}\left[\min \left(\left|Y(i)+\frac{4}{3}\right|^{2},\left|Y(i)-\frac{4}{3}\right|^{2}\right)\right]$

\section{TRANSMISSION CHANNEL}

In a wireless transmission system, the transmission channel introduces interferences and noise into the desired signal, limiting the capacity of the system. For the proper functioning of a given digital television standard, it is essential that it presents techniques that minimize these effects in order to the transmission to be viable. The two main causes of quality loss of a wireless transmission system are: the Additive White Gaussian Noise (AWGN) and the multipath [20].

The AWGN is present across the frequency spectrum, and cannot be avoided. In analog transmission, white noise causes quality loss of the received signal. As the desired signal power and the noise power ratio decreases, the image quality loss can be noticed. In digital television systems, the decrease in SNR causes an increase in the bit error probability [20].

In broadcasting systems, it is common for multiple copies of the same transmitted signal to arrive at the receiving antenna via different paths. Each of these paths has different attenuation and delay, which causes the received signal to be formed by the overlapping versions of various symbols coming from different paths [20].

For the simulation of different channels, in order to evaluate the behavior of the ISDB-T LDM system with diversity reception in conditions closer to the real situations, some channels representing the combination of reflected signals at different points must be tested [21].

- Channel A: simulates a reception situation with external antenna in places where the reflected signals are greatly attenuated.

- Channel B: Simulates signal with multiple echoes and large delays.

- Channel $\mathrm{C}$ : represents an intermediate reception condition between the channel A and channel D, where there are reflected signals with longer delays than in the Channel D.

- Channel D: represents a reception situation with internal antenna, considered of difficult reception due to the presence of strong reflected signals.

\section{IMPLEMENTATION AND RESULTS}

\section{A. Implementation}

The Core Layer, used in the transmission, was encoded with $\mathrm{CC}$ and RS codes. The coded signal was modulated in QPSK with Code Rate $=1 / 2$ [4].

The Enhanced Layer used the LDPC and BCH codes [22] and then was mapped with 64-QNUC, that has higher performance due to its symbols distribution and has significant gain in comparison to the traditional 64-QAM [13], [23]. The ISDB-T system operates with different code rates compared to the CRs used by the ATSC 3.0 system. Therefore, an adjustment was made in order to make the Non-Uniform Constellation compatible with ISDB-T system that uses the original 64-QAM with $\mathrm{CR}=1 / 2$, so the constellation was changed to $64-\mathrm{QNUC}$ with $\mathrm{CR}=8 / 15$ because this is the constellation that has the most similar code rate [4].

The Fig. 1 shows the LDM constellation for CL using QPSK with $\mathrm{CR}=1 / 2$, EL using 64-QNUC with $\mathrm{CR}=1 / 2$ and $\mathrm{IL}=6$ $\mathrm{dB}[4]$.

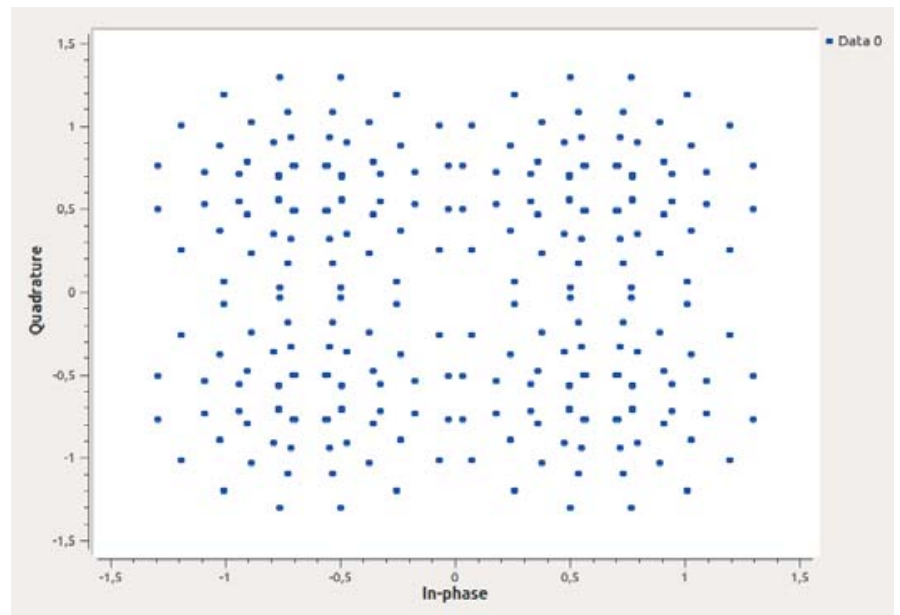

Fig. 1. Constellation with $\mathrm{CR}=1 / 2$ and $\mathrm{IL}=6 \mathrm{~dB}$ (Combined signal) [4].

The Fig. 2 shows the constellations of the four receiving branches in the LDM system with QPSK (CL), 64-QNUC (EL), $\mathrm{CR}=1 / 2, \mathrm{IL}=6 \mathrm{~dB}$ and $\mathrm{SNR}=20 \mathrm{~dB}$ before the MRC method [4]. These signals were transmitted by a GRC simulation. 

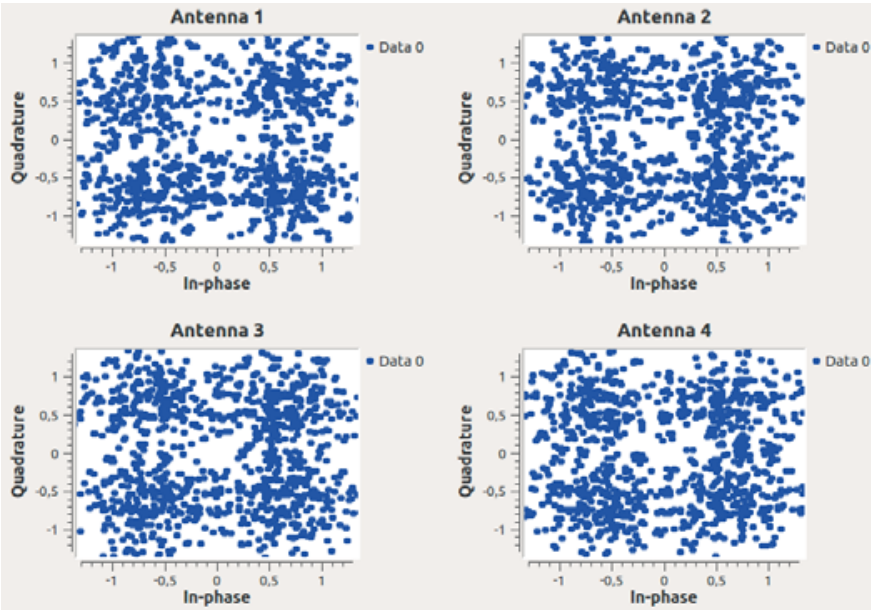

Fig. 2. Constellation (Combined signal) with $\mathrm{CR}=1 / 2, \mathrm{IL}=6 \mathrm{~dB}$ and $\mathrm{SNR}=$ $20 \mathrm{~dB}[4]$.

The Fig. 3 shows the constellation of the resulting signal at the output of the module that performs the MRC [4].

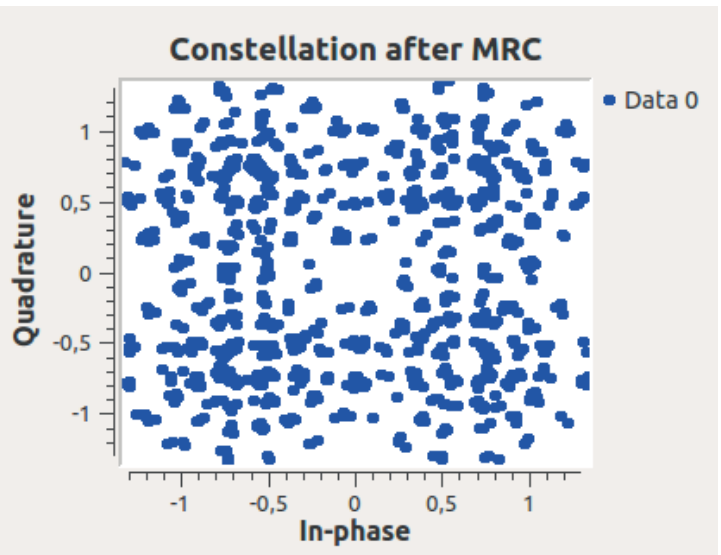

Fig. 3. Constellation (Combined signal) after MRC [4].

The ISDB-T LDM transmitter is presented in the Fig. 4 [4].
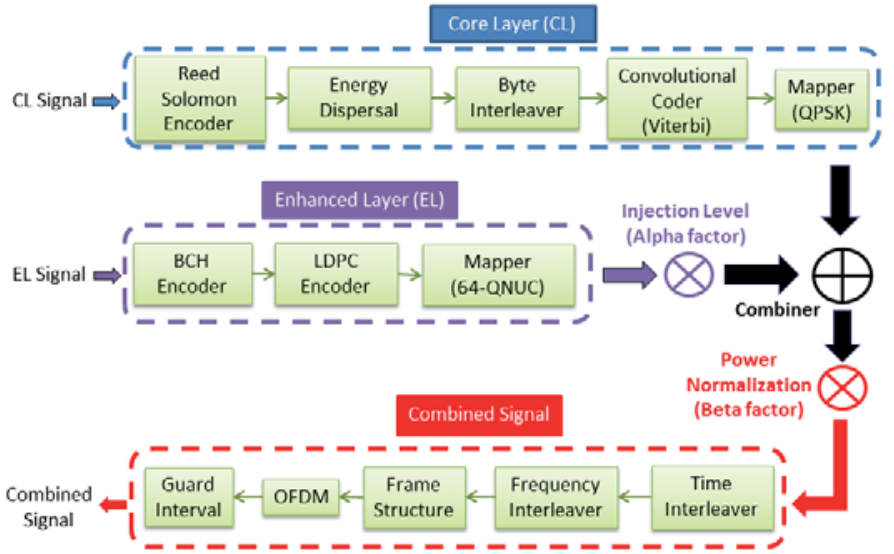

Fig. 4. ISDB-T LDM Transmitter [4].

In order to simulate the multipath effects, the channels A, B, $\mathrm{C}$, and $\mathrm{D}$ were used, as well as the addition of AWGN to find the SNR thresholds for each multipath channel configuration. The Fig. 5 shows the block diagram of the GRC that adds AWGN noise (Noise Source) with the signal (File Source) as well as the simulation of the multipath channels (Channel Model).

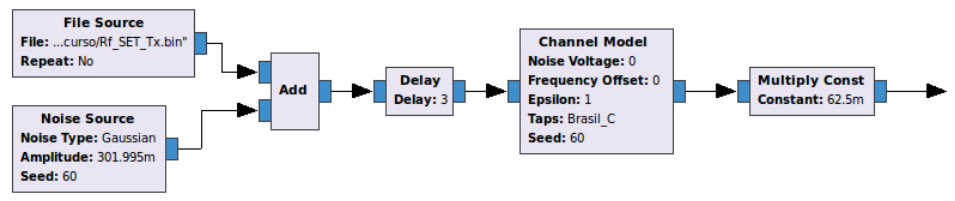

Fig. 5. Multipath channel block diagram.

After this process, the combined signals with Gaussian noise and multipath are sent to the demodulation module of the ISDBT LDM system.

The ISDB-T LDM receiver with reception diversity is shown in the Fig. 6 [4].

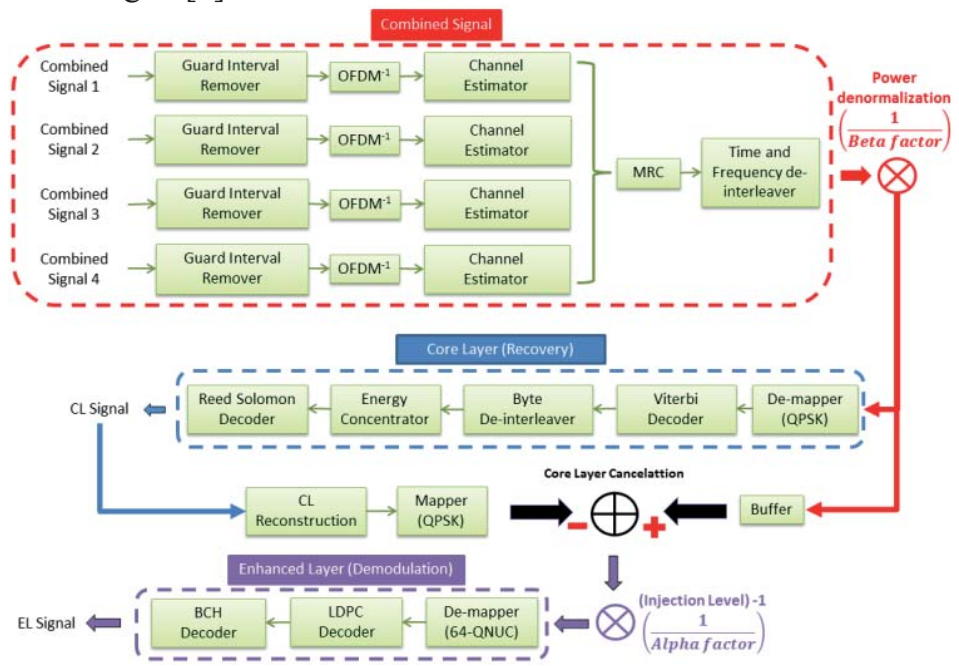

Fig. 6. ISDB-T LDM Receiver with MRC [4].

After the removal of the guard interval and OFDM demodulation, the signal is sent to the channel estimation stage. For a good performance in multipath environments, a 2D (two dimensions) channel estimator was used. It performs time and frequency interpolation. In addition, the interpolation method used was the Cubic Spline, which worked well, concatenated, with the maximal ratio combining stage [24].

To recover the Core Layer signal, a soft de-mapper, a Viterbi soft decoder, an energy concentrator, a RS decoder and a byte de-interleaving were used [4].

In the Enhanced Layer demodulator, a 64-QNUC de-mapper that uses approximately log-likelihood ratio was implemented [8]. These ratios are decoded with a LDPC decoder using $\mathrm{N}=$ 64800 and $\mathrm{CR}=1 / 2$. The $\mathrm{BCH}$ decoder used the same rate and followed the ATSC 3.0 standard for message and code word size, primitive and generator polynomials [13].

For the CL configuration with QPSK, CR $=1 / 2$ and RS + Viterbi, the data rate is $4.295 \mathrm{Mbps}$. For the EL configuration with 64-QNUC, CR $=1 / 2$ and $\mathrm{BCH}+\mathrm{LDPC}$, the data rate is $12.886 \mathrm{Mbps}$. Thus, with the use of LDM it is possible to reach the data rate of $17.181 \mathrm{Mbps}$, but there is also an increase in the minimum SNR for use in digital TV systems [8]. The MRC method reduces the negative effects of the use of LDM. With this method, the minimum SNR value decreases as the number of receiving antennas increases. 


\section{B. Results}

The source used was a Pseudo Random Binary Sequence 23 (PRBS 23). The number 23 came from the degree of the polynomial used to create this sequence. The maximum number of iterations on LDPC soft decoder was 50.

The tests consisted in measuring the SNR threshold for BER equals $3 \times 10^{-6}$ using QPSK with $\mathrm{CR}=1 / 2$ and 64-QNUC with $\mathrm{CR}=1 / 2$ for $1,2,3$ and 4 receive antennas in an Additive White Gaussian Noise (AWGN) channel with the multipath channels $\mathrm{A}, \mathrm{B}, \mathrm{C}$ and D.

The delay, inherent in the LDM technique, for CL was 437.04 ms and for EL was $655.56 \mathrm{~ms}$, which, respectively, correspond to 2 and 3 frames OFDM [8], [9]. It was also used GI = 1/16, TI $=200 \mathrm{~ms}, 13$ segments, and mode 3 from ISDB-T standard [17].

The SNR was measured by [4] for each configuration without using the LDM technique and multipath. In this case, just the AWGN was inserted by the channel. The results are presented in Table I [4]. The results shown were obtained for the QPSK using only the Layer A of the ISDB-T (Full Seg) with RS + Viterbi and for the 64-QNUC using BCH + LDPC. For the QPSK a gain of $5 \mathrm{~dB}$ was obtained with the use of MRC with 4 antennas. For the 64-QNUC, a gain of $6.9 \mathrm{~dB}$ was obtained in the same configuration of diversity.

TABLE I

MRC RESULTS IN AWGN CHANNEL.

\begin{tabular}{|c|c|c|c|c|}
\hline $\begin{array}{c}\text { Number } \\
\text { of } \\
\text { receive } \\
\text { antennas }\end{array}$ & Modulation & $\begin{array}{c}\text { Channel } \\
\text { Coder }\end{array}$ & $\begin{array}{c}\text { Code } \\
\text { Rate }\end{array}$ & $\begin{array}{c}\text { SNR } \\
\text { (dB) }\end{array}$ \\
\hline 1 & QPSK & RS+Viterbi & $1 / 2$ & 5.4 \\
\hline 2 & QPSK & RS+Viterbi & $1 / 2$ & 3.5 \\
\hline 3 & QPSK & RS+Viterbi & $1 / 2$ & 1.7 \\
\hline 4 & QPSK & RS+Viterbi & $1 / 2$ & 0.4 \\
\hline 1 & $64-Q N U C$ & BCH+LDPC & $1 / 2$ & 10.9 \\
\hline 2 & $64-Q N U C$ & BCH+LDPC & $1 / 2$ & 7.8 \\
\hline 3 & $64-Q N U C$ & BCH+LDPC & $1 / 2$ & 5.9 \\
\hline 4 & $64-Q N U C$ & BCH+LDPC & $1 / 2$ & 4.0 \\
\hline
\end{tabular}

Table II shows the results for LDM tests without multipath, that used CL with QPSK and CR = 1/2 and EL with 64-QNUC and $\mathrm{CR}=1 / 2$ for $1,2,3$ and 4 receive antennas [4]. For the QPSK (CL) a gain of $5.8 \mathrm{~dB}$ was obtained with the use of MRC with 4 antennas. For the 64-QNUC (EL), a gain of $3.8 \mathrm{~dB}$ was obtained in the same configuration of diversity.
TABLE II

MRC RESULTS USING LDM IN AWGN CHANNEL.

\begin{tabular}{|c|c|c|c|c|c|}
\hline $\begin{array}{c}\text { Number } \\
\text { of } \\
\text { receive } \\
\text { antennas }\end{array}$ & Modulation & $\begin{array}{c}\text { Channel } \\
\text { Coder }\end{array}$ & $\begin{array}{c}\text { Code } \\
\text { Rate }\end{array}$ & $\begin{array}{c}\text { IL } \\
(\mathbf{d B})\end{array}$ & $\begin{array}{c}\text { SNR } \\
(\mathbf{d B})\end{array}$ \\
\hline 1 & QPSK (CL) & RS+Viterbi & $1 / 2$ & 6 & 15.4 \\
\hline 2 & QPSK (CL) & RS+Viterbi & $1 / 2$ & 6 & 12.5 \\
\hline 3 & QPSK (CL) & RS+Viterbi & $1 / 2$ & 6 & 10.7 \\
\hline 4 & $\begin{array}{c}\text { QPSK (CL) } \\
1\end{array}$ & $\begin{array}{c}64-\mathrm{RS}+\text { Viterbi } \\
\text { (EL) }\end{array}$ & $1 / 2$ & 6 & 9.6 \\
\hline 2 & $\begin{array}{c}64-\mathrm{BNUC}+\mathrm{LDPC} \\
\text { (EL) }\end{array}$ & BCH+LDPC & $1 / 2$ & 6 & 20.4 \\
\hline 3 & $\begin{array}{c}64-\mathrm{QNUC} \\
\text { (EL) }\end{array}$ & BCH+LDPC & $1 / 2$ & 6 & 19.1 \\
\hline 4 & $\begin{array}{c}64-\mathrm{QNUC} \\
(\mathrm{EL})\end{array}$ & BCH+LDPC & $1 / 2$ & 6 & 16.6 \\
\hline
\end{tabular}

Table III shows the results for the configuration without LDM technique and with multipath, for 1, 2, 3 and 4 receiving antennas and $\mathrm{CR}=1 / 2$.

For the QPSK with Channel A a gain of $0.8 \mathrm{~dB}$ was obtained with the use of MRC with 4 antennas. For Channel B the gain was $1.7 \mathrm{~dB}$, for the Channel $\mathrm{C}$ was $0.8 \mathrm{~dB}$ and for Channel D was $1.6 \mathrm{~dB}$.

For the 64-QNUC with Channel A a gain of $4.9 \mathrm{~dB}$ was obtained in the same configuration of diversity. For Channel B the gain was $3.2 \mathrm{~dB}$, for the Channel $\mathrm{C}$ was $4.6 \mathrm{~dB}$ and for Channel D was $2.5 \mathrm{~dB}$.

TABLE III

MRC RESUlts IN AWGN/Multipath ChanNELS.

\begin{tabular}{|c|c|c|c|c|c|c|}
\hline \multirow{2}{*}{$\begin{array}{c}\text { Number } \\
\text { of receive } \\
\text { antennas }\end{array}$} & \multirow{2}{*}{ Modulation } & \multirow{2}{*}{$\begin{array}{c}\text { Channel } \\
\text { Coder }\end{array}$} & $\begin{array}{c}\text { Channel } \\
\boldsymbol{A}\end{array}$ & $\begin{array}{c}\text { Channel } \\
\boldsymbol{B}\end{array}$ & $\begin{array}{c}\text { Channel } \\
\text { C }\end{array}$ & $\begin{array}{c}\text { Channel } \\
\boldsymbol{D}\end{array}$ \\
\hline 1 & QPSK & RS+Viterbi & 8.1 & 14.3 & 8.2 & 15.7 \\
\hline 2 & QPSK & RS+Viterbi & 7.6 & 13.7 & 7.6 & 15.1 \\
\hline 3 & QPSK & RS+Viterbi & 7.4 & 12.8 & 7.5 & 14.5 \\
\hline 4 & QPSK & RS+Viterbi & 7.3 & 12.6 & 7.4 & 14.1 \\
\hline 1 & $64-$ QNUC & BCH+LDPC & 12.0 & 15.5 & 12.1 & 16.6 \\
\hline 2 & $64-$ QNUC & BCH+LDPC & 9.5 & 15.1 & 9.7 & 15.5 \\
\hline 3 & $64-$ QNUC & BCH+LDPC & 8.0 & 13.6 & 8.3 & 14.6 \\
\hline 4 & $64-$ QNUC & BCH+LDPC & 7.1 & 12.3 & 7.5 & 14.1 \\
\hline
\end{tabular}


Table IV shows the results for LDM tests with multipath, that used CL with QPSK and CR $=1 / 2$, EL with 64-QNUC and CR $=1 / 2$ and Injection Level $=6 \mathrm{~dB}$.

For the QPSK (CL) with Channel A a gain of $5.8 \mathrm{~dB}$ was obtained with the use of MRC with 4 antennas. For Channel B the gain was $2.5 \mathrm{~dB}$, for the Channel $\mathrm{C}$ was $5.8 \mathrm{~dB}$ and for Channel D was $2.1 \mathrm{~dB}$.

For the 64-QNUC (EL) with Channel A a gain of $2.2 \mathrm{~dB}$ was obtained in the same configuration of diversity. For Channel B the gain was $2.8 \mathrm{~dB}$, for the Channel $\mathrm{C}$ was $2.3 \mathrm{~dB}$ and for Channel D was $2.5 \mathrm{~dB}$.

TABLE IV

MRC RESUlts Using LDM IN AWGN/MULTIPATH CHANNELS.

\begin{tabular}{|c|c|c|c|c|c|c|c|}
\hline \multirow{2}{*}{$\begin{array}{c}\text { Number } \\
\text { of } \\
\text { receive } \\
\text { antennas }\end{array}$} & \multirow[b]{2}{*}{ Modulation } & \multirow[b]{2}{*}{$\begin{array}{c}\text { Channel } \\
\text { Coder }\end{array}$} & \multirow[b]{2}{*}{$\begin{array}{c}I L \\
(d B)\end{array}$} & \multicolumn{4}{|c|}{$S N R(d B)$} \\
\hline & & & & $\begin{array}{c}\text { Channe } \\
\text { A }\end{array}$ & $\begin{array}{c}\text { Channel } \\
B\end{array}$ & $\begin{array}{c}\text { Channel } \\
\text { C }\end{array}$ & $\begin{array}{c}\text { Channel } \\
D\end{array}$ \\
\hline 1 & $\begin{array}{l}\text { QPSK } \\
\text { (CL) }\end{array}$ & RS+Viterbi & 6 & 16.1 & 16.6 & 16.2 & 17.4 \\
\hline 2 & $\begin{array}{l}\text { QPSK } \\
\text { (CL) }\end{array}$ & RS+Viterbi & 6 & 13.1 & 15.0 & 13.1 & 16.2 \\
\hline 3 & $\begin{array}{l}\text { QPSK } \\
\text { (CL) }\end{array}$ & RS+Viterbi & 6 & 11.3 & 14.3 & 11.4 & 15.7 \\
\hline 4 & $\begin{array}{l}\text { QPSK } \\
\text { (CL) }\end{array}$ & RS+Viterbi & 6 & 10.3 & 14.1 & 10.4 & 15.3 \\
\hline 1 & $\begin{array}{l}\text { 64-QNUC } \\
\text { (EL) }\end{array}$ & $\mathrm{BCH}+\mathrm{LDPC}$ & 6 & 19.9 & 20.0 & 20.1 & 20.7 \\
\hline 2 & $\begin{array}{l}\text { 64-QNUC } \\
\text { (EL) }\end{array}$ & $\mathrm{BCH}+\mathrm{LDPC}$ & 6 & 19.3 & 18.9 & 19.2 & 19.5 \\
\hline 3 & $\begin{array}{l}\text { 64-QNUC } \\
\text { (EL) }\end{array}$ & $\mathrm{BCH}+\mathrm{LDPC}$ & 6 & 18.1 & 17.8 & 18.2 & 18.7 \\
\hline 4 & $\begin{array}{c}\text { 64-QNUC } \\
\text { (EL) }\end{array}$ & $\mathrm{BCH}+\mathrm{LDPC}$ & 6 & 17.7 & 17.2 & 17.8 & 18.2 \\
\hline
\end{tabular}

\section{CONCLUSION}

The LDM implementation into ISDB-T is important to secure the compatibility with the traditional system in case of new broadcast technology transition. However, there is an increase of the minimum SNR values required for the correct reception of the transmitted signal when the LDM technique is used. Thus, it would be possible to use the CL of the LDM to transmit the ISDB-T and, at the same time, transmit a new technology in the EL.

With the use of more than one receiving antenna using the MRC method, it is possible to improve robustness and the data rates of each layer of the system. For each added antenna, a gain was obtained as shown in Tables I, II, III and IV.

The implementation of NUC modulators, demodulators and the BCH and LDPC codes contributed to the system's improvement.

The enhanced version of ISDB-T LDM system with reception diversity allows to transmit more data and it is more robust against noise and multipath interferences. With its use, it was possible to reach a data rate of $17.181 \mathrm{Mbps}$ with $\mathrm{CR}=1 / 2$. This data rate can be increased with the use of different code rates [8]. With the use of multiple receiving antennas and the MRC method, it is possible to compensate for the increase the minimum SNR value for the correct reception of the signals in a digital TV broadcast system.

The tests showed that even in a multipath environment with extreme degradations in the transmitted signal, it was possible to recover it efficiently with the use of MRC, LDM, NonUniform Constellations, as well as powerful codes such as LDPC.

\section{ACKNOWLEDGMENT}

The authors would like to thank PPGEEC and their colleagues at Mackenzie's Digital TV Research Laboratory.

\section{REFERENCES}

[1] G. J. Foschini and M. J. Gans, "On limits of wireless communications in a fading environment when using multiple antennas," Wireless Personal Communications, vol. 6, pp. 311-335, 1998.

[2] A. Sato, T. Shitomi, T. Takeuchi, M. Okano and K. Tsuchida, "Transmission performance evaluation of LDPC coded OFDM over actual propagation channels in urban area. Examination for nextgeneration ISDB-T," 2017 IEEE International Symposium on Broadband Multimedia Systems and Broadcasting (BMSB), pp. 1-5, June 2017.

[3] Y. Wu, B. Rong, K. Salehian and G. Gagnon, "Cloud Transmission: A New Spectrum-Reuse Friendly Digital Terrestrial Broadcasting Transmission System," IEEE Transactions on Broadcasting, vol. 58, no. 3, pp. 329-337, September 2012.

[4] R. S. Rabaça, C. Akamine, G. H. M. G. d. Oliveira and Y. P. Maciel, "Implementation of LDM/ISDB-T broadcast system using diversity at reception," 2017 IEEE International Symposium on Broadband Multimedia Systems and Broadcasting (BMSB), pp. 1-4, 8 June 2017.

[5] L. Fay, L. Michael, D. Gómez-Barquero, N. Ammar and M. W. Caldwell, "An Overview of the ATSC 3.0 Physical Layer Specification," IEEE Transactions on Broadcasting, vol. 62, pp. 159171, March 2016.

[6] T. K. Roy and M. Morshed, "Performance analysis of pdc over rayleigh fading channel for ofdm system," International Journal of Computing Communication and Networking Research, vol. 2, pp. 1-6, January 2013.

[7] B. Vucetic and J. Yuan, Space-time Coding, 1 ed., John Wiley and Sons Ltd, 2003.

[8] G. H. M. G. d. Oliveira, C. Akamine and Y. P. Maciel, "Implementation of ISDB-T LDM broadcast system using LDPC codes," 2016 IEEE International Symposium on Broadband Multimedia Systems and Broadcasting (BMSB), pp. 1-4, June 2016.

[9] L. F. d. Silva, C. Akamine, Y. P. Maciel, G. Bedicks and E. L. Horta, "A proposal to use cloud transmission technique into the ISDB-T system," 2015 IEEE International Symposium on Broadband Multimedia Systems and Broadcasting, pp. 1-5, 2015.

[10] GNU Radio, "GNU Radio Companion," [Online]. Available: https://wiki.gnuradio.org/index.php/Main_Page. [Accessed 29 July 2017].

[11] S. I. Park, H. M. Kim, P. Angueira and Y. Wu, "Hardware Implementation and Complexity Analysis of Layered Division Multiplexing (LDM) System for ATSC 3.0," NAB Broadcast Engineering Conference, pp. 77-81, 2015.

[12] L. Zhang, Y. Wu, W. Li, H. M. Kim, S. Park, P. Angueira, J. Montalban and M. Velez, "Channel capacity distribution of LayerDivision-Multiplexing system for next generation digital broadcasting transmission," 2014 IEEE International Symposium on Broadband Multimedia Systems and Broadcasting, pp. 1-6, 2014.

[13] Advanced Television Systems Commitee (ATSC), ATSC Candidate Standard: Physical Layer Protocol, A/322, Apr. 2016. 
[14] J. Montalban, B. Rong, Y. Wu, L. Zhang, P. Angueira and M. Velez, "Cloud Transmission frequency domain cancellation," 2013 IEEE International Symposium on Broadband Multimedia Systems and Broadcasting (BMSB), pp. 1-4, 2013.

[15] R. Asvadi, A. H. Banihashemi and M. Ahmadian-Attari, "Lowering the Error Floor of LDPC Codes Using Cyclic Liftings," IEEE Transactions on Information Theory, vol. 57, no. 4, pp. 2213-2224, April, 2011.

[16] C. Akamine, Y. Iano, G. d. M. Valeira and G. Bedicks, "ReMultiplexing ISDB-T BTS Into DVB TS for SFN," IEEE Transactions on Broadcasting, vol. 55, no. 4, pp. 802-809, December 2009.

[17] Association of Radio Industries and Businesses (ARIB), Transmission System for Digital Terrestrial Broadcasting, STD-B31, V1.6 E2, Nov. 2005.

[18] Brazilian Association of Technical Standards - Associação Brasileira de Normas Técnicas (ABNT), Digital terrestrial television - Transmission system, NBR 15601, Nov. 2007.

[19] R. J. L. Olandim and C. Akamine, "Spatial diversity at reception in ISDB-Tb systems," Proceedings of the Symposium on Signal Processing of UNICAMP, vol. 1, pp. 1-4, 2014.

[20] R. J. L. Olandim, Spatial diversity at reception in ISDB-Tb systems, Sao Paulo: Mackenzie Presbyterian University, 2015.

[21] L. L. Mendes and S. A. Fasolo, "Introduction to Digital Television," pp. 1-6, Technical report, INATEL, 2002.

[22] Mackenzie Presbyterian University, "Robustness of digital TV systems to interference," Journal of Engineering and Computing, vol. 5, $\mathrm{n}^{\circ} 5$, 2004.

[23] European Telecommunications Standards Institute (ETSI), Digital Video Broadcasting (DVB); Second generation framing structure, channel coding and modulation systems for Broadcasting, Interactive Services, News Gathering and other broadband satellite applications (DVB-S2), EN 302 307, V1.2.1, Aug. 2009.

[24] N. S. Loghin, J. Zöllner, B. Mouhouche, D. Ansorregui, J. Kim and S I. Park, "Non-Uniform Constellations for ATSC 3.0," IEEE Transactions on Broadcasting, vol. 62, no. 1, pp. 197-203, March 2016.

[25] T. M. Sapia and C. Akamine, "Channel estimation evaluation in an ISDB-T system using GNU Radio," Conference on Electronics, Telecommunications and Computers, pp. 1-2, Dec. 2016.

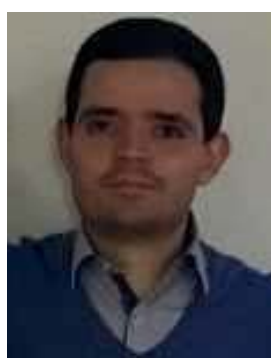

Ricardo Seriacopi Rabaça received the B.Sc. and M.Sc. degrees in electrical engineering from the Mackenzie Presbyterian University, Sao Paulo, Brazil, in 2013 and 2017, respectively. His fields of study are telecommunications, broadcasting and Software Defined Radio.

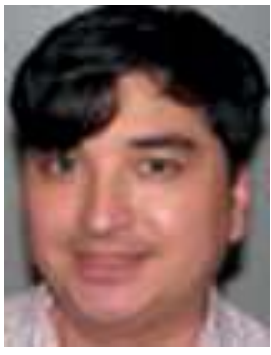

Cristiano Akamine received his B.Sc. degree in Electrical Engineering from Mackenzie Presbyterian University, Sao Paulo, Brazil, in 1999. He received his M.Sc. and Ph.D. degree in Electrical Engineering from the State University of Campinas (UNICAMP), Sao Paulo, Brazil, in 2004 and 2011 respectively. He is a professor of Embedded Systems, Software Defined Radio and Advanced Communication Systems at Mackenzie Presbyterian University. $\mathrm{He}$ is a researcher in the Digital TV Research Laboratory at Mackenzie Presbyterian University since 1998, where he has had the opportunity to work with many digital TV systems. His research interests are in a system on chip for broadcast TV and Software Defined Radio.

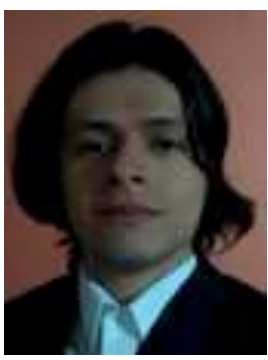

George Henrique Maranhão Garcia de Oliveira received the B.Sc. and M.Sc. degrees in electrical engineering from the Mackenzie Presbyterian University, Sao Paulo, Brazil, in 2014 and 2016, respectively. He has experience in Electrical Engineering with emphasis on characterization of ISDB-T receivers, testing and configuration of SFN networks and LTE interference tests on digital TV. He also has experience in Electrical, Magnetic and Electronic Measurements. His fields of study are broadcasting, Error correction codes and Software Defined Radio.

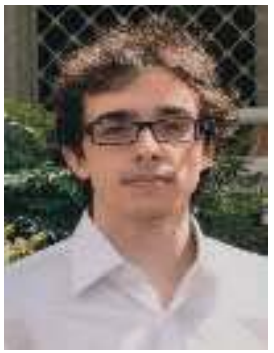

Thiago Montanaro Sapia received the B.Sc. and M.Sc. degrees in electrical engineering from the Mackenzie Presbyterian University, Sao Paulo, Brazil, in 2014 and 2016, respectively. His fields of study are broadcasting and Software Defined Radio. 